Running head: PROTOTYPICAL MODESTY

\title{
Everyday Conceptions of Modesty:
}

\section{A Prototype Analysis}

\author{
Aiden P. Gregg \\ Claire M. Hart \\ Constantine Sedikides \\ University of Southampton
}

Madoka Kumashiro

Goldsmiths College, University of London 
Abstract

Good theoretical definitions of psychological phenomena are not only rigorously formulated but also provide ample conceptual coverage. To assess the latter, we empirically surveyed everyday conceptions of modesty in a combined US/UK sample. In Study 1, participants freely generated multiple exemplars of modesty that judges subsequently sorted into superordinate categories. Exemplar frequency and priority served respectively as primary and secondary indices of category prototypicality that enabled central, peripheral, and marginal clusters to be identified. Follow-up studies then confirmed the ordinal prototypicality of these clusters with the aid of both explicit (Studies 2 and 3) and implicit (Study 3) methodologies. Modest people emerged centrally as humble, shy, solicitous, and not boastful, and peripherally as honest, likeable, not arrogant, attention-avoiding, plain, and gracious. Everyday conceptions of modesty also spanned both mind and behavior, interestingly emphasized agreeableness and introversion, and predictably incorporated an element of humility. 


\section{Everyday Conceptions of Modesty:}

\section{A Prototype Analysis}

Empirical psychologists who investigate everyday social phenomena face a perennial problem: how to define adequately the phenomena that they study from a theoretical point of view (Cronbach \& Meehl, 1955; Wegener \& Fabrigar, 2004). We submit that one reason why adequate theoretical definitions prove elusive is that they must simultaneously satisfy two criteria that tend to be mutually exclusive: rigor and coverage. We begin by illustrating this difficulty for the construct of modesty, the focus of this article. This illustration is important to our rationale for the reported research.

Rigor and Coverage

Rigor. A good definition should be clear and coherent; it should fit neatly into a broader theoretical framework; and it should lend itself easily to measurement and manipulation. Suppose we were to define modesty as either (a) "not going overboard with self-love," or as (b) "the dispositional tendency to evaluate oneself globally in an intermediately positive way" (Sedikides, Gregg, \& Hart, 2007, p. 164). Although both definitions may have some truth to them, the latter is scientifically superior. It features terms that are more concrete and exact; it makes contact with existing research literatures (self-esteem: Sedikides \& Gregg, 2003; attitudes: Petty \& Wegener, 1998); and it suggests practical avenues of empirical investigation (e.g., operationalizations of moderate self-evaluation).

A further mark of definitional rigor is that the conditions necessary or sufficient to qualify something as an instance of a phenomenon can be readily identified (Smith \& Medin, 1981). For example, according to definition (b), it is clear that a person cannot be modest unless they have a moderately favorable view of themselves as a whole, and one that persists through time even though it need not be invariably present. Moreover, meeting these conditions together is perhaps 
adequate to ensure that a person truly is modest. In contrast, definition (a), being comparatively vague, provides no similarly necessary or sufficient criteria.

Coverage. However, rigor alone is not enough. A good definition should also comprehensively capture a phenomenon of interest; it should faithfully map on to its manifold facets; and it should reveal rather than conceal its richness. Definition (b), for all its virtues, leaves much unspecified. For example, this definition might be usefully expanded by describing the various domains in which modesty can be manifested. Thus, a modest person is liable to believe moderately favorable facts about themselves, is liable to feel moderately well-disposed towards themselves, and is liable to behave in moderately confident ways. Such an expanded definition does better justice to the complexity of the phenomenon. On the other hand, it also creates a problem: What happens if people manifest inconsistency between different domains? What if they were to self-enhance in private but to self-efface in public? There is no simple answer to such a question. Indeed, one mark of definitional coverage is that the conditions necessary or sufficient to qualify something as an instance of a phenomenon cannot be readily identified. This is because the phenomenon itself, as naturally construed, is inherently fuzzy, involving an array of elements that bear a family resemblance to one another rather than having any single unifying attribute (Rosch, 1978; Wittgenstein, 1953). Hence, any given instance qualifies as a more or less representative exemplar of a phenomenon, rather than as a clear-cut example or non-example of it. Thus, people who evaluate themselves moderately in both public and private would provide better exemplars of modesty — exemplars closer to the prototype — than those who do so only in public or private.

\section{An Optimal Compromise}

Everyday concepts should certainly not dictate the content of scientific constructs. But neither should scientific constructs gloss over everyday concepts. The former assertion is uncontroversial. Scientific constructs (at least, those that survive repeated attempts at falsification; 


\section{Prototypical Modesty}

Popper, 1959) are superior to everyday concepts, because they parse the world more accurately. For example, although rust and fire are superficially dissimilar, chemical science proves them to be fundamentally allied: both are forms of oxidation. Moreover, as intellectual progress is made, everyday concepts should gradually accommodate themselves to scientific ones. Suppose a psychologist were to discover that modest people habitually imagined themselves as superheroes, because they could only satisfy in private egocentric desires that immodest people can satisfy in public. ${ }^{1}$ The concept of modesty, while retaining many of its fundamental features, might then expand to include another facet, specifically, a fondness for flattering fantasy. Yet, whatever modifications it might undergo, the everyday concept of modesty must still preserve some of its original identity. Suppose a psychologist devised a definition of modesty utterly at odds with commonsense (e.g., "Modesty is the propensity to laugh out loud"). No research carried out using this definition could shed any empirical light on modesty, for the simple reason that it would differ too fundamentally from how modesty is commonly understood. To be useful, then, a scientific construct must continue to reflect the everyday construct from which it derives. If it strays too far from its linguistic roots, it runs the risk of irrelevance.

Thus, when trying to develop a good theoretical definition of a phenomenon, a compromise needs to be negotiated between rigor and coverage - between the neat exactitude of scientific constructs and the obliging looseness of everyday concepts. Several authors have already attempted to define modesty stipulatively, for the purpose of conducting new empirical studies (Cialdini, Wosinska, Dabul, Whestone-Dion, \& Heszen, 1998) or of integrating existing findings (Sedikides et al., 2007). However, these definitions, being definitions, could be faulted for overly prioritizing rigor. In this article, then, we attempt to redress the imbalance by empirically surveying what people generally understand by "modesty," in order to enable us to modify our working definition of modesty in the direction of improved coverage. 
Why Should Modesty Be Surveyed?

The above general points could be made with respect to any psychological characteristic. Why, then, single out modesty for scrutiny? There are at least three reasons to do so.

First, the construct of modesty has recently been a focus of burgeoning empirical and theoretical research - a veritable "hot" topic - particularly with the resurgence of interest in positive psychology and character virtues (Exline, Campbell, Baumeister, Joiner, \& Krueger, 2004; Gilbert, 2006; Neff, 2003; Peterson, Park, \& Seligman, 2006), in the potential disadvantages of self-enhancement and high self-esteem (Baumeister, Campbell, Krueger, \& Vohs, 2003; Dunning, Heath, \& Suls, 2004; Sedikides et al., 2007), and in cultural variations in self-construal (Bond, Kwan, \& Li, 2000; Chen, Bond, \& Tang, 2006; Sedikides, Gaertner, \& Toguchi, 2003). In addition, recent analyses of personality structure (Ashton, Lee, \& Goldberg, 2004), extending across different cultures (Ashton, Lee, Perugini et al., 2004), suggest that personality traits arrange themselves, not into a fundamental quintet of factors (i.e., the "Big Five"), but rather into a fundamental sextet, with honesty-humility being the "extra" factor. Moreover, one of the facet-level subscales assessing this factor is expressly entitled Modesty (the other three being Sincerity, Fairness, and Greed Avoidance). Thus, an empirical survey of the construct of modesty is both salutary and timely.

Second, disagreement exists over how the construct of modesty should be construed. The primary difference of opinion lies along the public-private continuum: whereas some researchers emphasize the interpersonal nature of modesty, as a form of behavioral self-presentation, others emphasize the intrapersonal nature of modesty, as form of psychological self-evaluation. For example, Cialdini et al. (1998) define modesty as the "public [italics added] under-representation of one's favorable traits and abilities (p. 473)" whereas Sedikides et al. (2007) define modesty as "a moderate self-view [italics in original]" emphasizing its "intrapsychic reality (p. 164)." Reflecting 
this variety, standard dictionaries define "modesty" in two ways, primarily as an attribute of personality, and only then as a demure demeanor (Guarlnik, 1984; Mish, 1991; Pearsall, 2001). In a recent review, Exline, Campbell, and colleagues (2004) ecumenically note that "the term modesty refers primarily to the moderate estimation of one's merits or achievements and also extends into other issues relating to propriety in dress and social behavior (p. 463).” Thus, an empirical survey of modesty would help to clarify the relative emphasis that might be placed on its public and private facets.

Third, with a few exceptions (Cialdini et al., 1998; Tice, Butler, Muraven, \& Stillwell, 1995), a good deal of research on modesty has attempted to characterize it, either distinctively or comparatively, as an East-Asian phenomenon (Bond, Leung, \& Wan, 1982; Crittenden, 1991; Gu, 1990; Heine, Lehman, Markus, \& Kitayama, 1999). However, modesty has played an important historical role, and is highly valued, in Western culture too (Eagly \& Acksen, 1971; Exline, Campbell et al., 2004; Jones \& Wortman, 1973; Schlenker, 1980). Thus, an independent empirical survey of modesty within Western culture is warranted, thereby helping to redress an earlier imbalance of emphasis.

How Should Modesty Be Surveyed?

One way to characterize our intended approach to surveying modesty is to compare and contrast it with the recent approach of Exline and Geyer (2004) to surveying humility — a concept clearly allied to, although not necessarily redundant with, modesty. Just as there is controversy among researchers over whether the intrapsychic or interpersonal aspects of modesty should be emphasized, so there is controversy among researchers over whether humility should be regarded as a character weakness or strength. On the one hand, humility is synonymous with words such as meekness, subservience, and abasement (http://thesaurus.reference.com/search? $q=$ humility), and is also etymologically related to the word humiliation. ${ }^{2}$ Notoriously, Nietzsche $(1887 / 1989)$ argued 
that humility was a symptom of the "slave-morality" that stood in the way of self-confident autonomy and ethical maturity. On the other hand, major religious figures (Matt. 5:5 King James Version) and recent empirical researchers (Exline, Campbell et al., 2004; Tangney, 2000) have contended that humility is a moral virtue or desirable trait. What, then, do laypeople believe? Exline and Geyer (2004) generally found that most of their participants construed humility favorably. Were it not for sample limitations - their participants were largely Christian undergraduates - their findings would imply that a good definition of humility should incorporate a preponderance of positive elements.

As regards methodology, Exline and Geyer (2004) used a mixture of closed-ended and open-ended measures. Specifically, they had participants (a) rate how favorably they regarded humility, how closely it resembled several pre-selected personality traits, and how likely a humble person was to exhibit other pre-selected traits; and (b) provide definitions of humility, describe a humble person, and list situations where they personally had felt humble. Thus, their approach had the merit of breadth: their multiple indices provided converging evidence of lay perceptions of humility.

We, however, took a different tack and adopted an intensively open-ended approach. In particular, we attempted not only to generate a general picture of how a modest person is seen but also to characterize which traits are seen as more or less prototypical of such a person. Moreover, to maximize the information at our disposal, we also used two indices of prototypicality: the frequency with which participants generated exemplars (the more common index) and the priority with which they listed them (the less common index). In addition, we (a) devised and checked our scheme for categorizing exemplars using four separate raters, and (b) obtained exemplars from a relatively diverse sample (students and non-students, American and British). Finally, having arrived at clusters containing exemplars of greater or lesser prototypicality, we sought to confirm in 


\section{Prototypical Modesty}

9

two follow-up studies that these clusters were prototypical in the predicted direction, using both binary choices and the time taken to make them as relevant evidence. Thus, our approach had the merit of depth: our rigorous reduction of empirical exemplars afforded us more detailed insight into everyday conceptions of modest people.

\section{Study 1}

\section{Overview}

To characterize the everyday concept of modesty, we attempted to distil its prototype from a set of empirically generated exemplars (for a similar methodologies, see Broughton, 1984; Buss \& Craik, 1985; Hassebrauck, 1997). In particular, we instructed participants from two different populations to list the characteristics (exemplars) that they regarded as typifying a modest person. We then sorted these exemplars into higher-order categories, and counted the number of exemplars per category. The resulting index of exemplar frequency served as our primary index of category prototypicality. Next, we attempted to separate exemplars implying more prototypical categories from exemplars implying more idiosyncratic categories. In particular, we retained exemplars only if they belonged to categories common to both samples, and only if they occurred with a frequency exceeding the median number of exemplars per category. Finally, among the categories that we retained, we then attempted to identify several discrete higher-order clusters, containing categories of greater or lesser prototypicality. To do so, we looked for ostensible breaks in the frequency distribution to locate relevant boundaries. We then used supplementary information, on the order in which participants listed exemplars, to adjust our final determinations.

$$
\text { Method }
$$

\section{Participants}

Two samples of volunteers contributed data. The first comprised 79 UK employees $\left(\mathrm{M}_{\mathrm{AGE}}\right.$ $=34.0 ; \mathrm{SD}_{\mathrm{AGE}}=12.6 ; 72 \%$ female) working in the financial sector and the civil service. The 
second comprised 118 US undergraduate students $\left(\mathrm{M}_{\mathrm{AGE}}=19.7 ; \mathrm{SD}_{\mathrm{AGE}}=2.6 ; 79 \%\right.$ female $)$ attending the University of North Carolina at Chapel Hill.

\section{Procedure}

Participants were told that they were taking part in a larger study about what people have in mind when they hear and use words. By way of example, they were initially advised that someone might list words like freedom and elections as characteristics of democracy, and phrases like orders others around and takes charge as characteristics of a dominant person. Participants were then asked to write down, within four minutes on the sheet supplied, all the characteristics that they believed would distinguish a modest person, using single words or short phrases. They were further advised that there were no right or wrong answers, and that their personal opinion was of particular interest to the researchers.

\section{Preliminary Data Reduction}

Categorization scheme. The exemplars generated by UK participants were coded by two independent judges into two provisional sets of categories. The provisional categories were devised on the basis of (a) the repetition of lexically similar exemplars, (b) the ostensible semantic relatedness of different exemplars, and (c) the judges' prior knowledge about how personality traits might cluster (e.g., into the "Big Five;" McCrae \& Costa, 1997). Initial agreement between the judges was moderate (55\%) - unsurprisingly, given the breadth of the modesty concept. All disagreements were then resolved through discussion. The validity of the resulting categorical scheme was then tested in two ways. First, another independent judge rated, using a three point scale $(1=$ Fitting, $0=$ Debatable, $-1=$ Unfitting $)$, how well each of the 469 exemplars generated by UK participants fitted into each of the 100 original categories devised by the two previous judges. Reassuringly, $92 \%$ of the categorizations were deemed fitting, $6 \%$ debatable, and only $2 \%$ unfitting. Second, another independent judge sorted each of the exemplars into what they regarded 
as the best suited original category, a sterner test of validity. The original and new categorizations matched each other a respectable $83 \%$ of the time.

Next, both original judges attempted to extend this categorization scheme. Of the 100 original categories devised using UK exemplars, 48 were judged applicable to US exemplars (implying that both samples categorically overlapped approximately half the time). The judges then devised 54 further categories to subsume any remaining US exemplars. The same two tests of validity as above were then carried out on the new extended categorization scheme. In all, US participants generated 684 exemplars, falling into 102 categories. According to an independent judge, $86 \%$ of these categories were fitting, $8 \%$ debatable, and $6 \%$ unfitting. Moreover, another independent judge, using the original scheme, made identical categorizations $81 \%$ of the time.

Counting exemplars per category. As mentioned above, exemplar frequency - the number of exemplars subsumed under each category—served as our primary index of prototypicality. However, a complication arose: How should we code multiple exemplars generated by the same participant falling into the same category?

On the one hand, such exemplar duplication provides only redundant semantic information. For example, if a participant successively reported that a modest person was "not bigheaded" and "not full of themselves," then they would essentially be twice characterizing a modest person as being not arrogant (the category label). On this view, duplicate exemplars should be ignored.

On the other hand, such exemplar duplication provides useful psychological information. In their search for a new characteristic to report, participants may have reiterated one similar to, or synonymous with, a previous characteristic, because of the continuing accessibility of the overarching category. For example, reporting "not full of themselves" after "not bigheaded" would suggest that a participant regards the category not arrogant as being highly applicable to a modest person. On this view, duplicate exemplars should be acknowledged. 
Given that a reasonable argument can be advanced for both including and excluding duplicate exemplars, we decided to do both. We report the results side-by-side, subject to further statistical examination.

Deriving common categories. Our use of two divergent participant samples—drawn from different Western nations and occupational backgrounds - was intentional. First, we wanted to cover a relatively broad range of participants to facilitate any future extrapolations to a wider population. Second, the use of two samples gave us a powerful tool for eliminating at a stroke a multitude of non-prototypical categories. Specifically, we could designate as unrepresentative any category not shared by both the US and the UK sample (i.e., implied by at least one exemplar in both samples). This cross-sample "sieve" permitted us to discard 52 of the original 100 UK categories, and 54 of the original 102 US categories, leaving 48 common categories whose prototypicality could subsequently be estimated.

\section{Estimating Prototypicality}

Exemplar frequency. Exemplar frequency data for all common categories was averaged across both samples. The resulting distribution of exemplar frequency was very positively skewed, whether idiosyncratic duplicates were included (skewness $=3.1$; range $=1-78$; median $=5.3)$ or excluded $($ skewness $=2.5$, range $=1-45$; median $=4.5)$. This skewness suggested — promisinglythat the everyday conceptions of modesty were primarily defined by a small cluster of "outlying" categories. To pin down the prototypical dimensions of modesty, we began by discarding all categories whose exemplar frequencies fell short of the median, thus leaving either 24 (duplicates included) or 23 (duplicates excluded) categories. We then attempted to divide these remaining categories into three distinct higher-order clusters — central, peripheral, and marginal—reflecting the degree to which they exemplified the everyday concept of modesty. To identify natural divisions, we inspected adjacent exemplar frequency values, looking to identify ostensible breaks. 
Whether duplicates were included or excluded, an ostensible break emerged between the fourth and fifth categories, and another between the tenth and eleventh categories. Moreover, whether duplicates were included or excluded, the ostensible breaks emerged in the same place. We therefore felt justified in designating the former cluster as central, and the latter as peripheral. We additionally designated all remaining categories as marginal.

The four central categories comprised humble (humble), shy (bashful, introverted, quiet, reserved, retiring, shy), not boastful (doesn't brag, not boastful), and solicitous (caring, considerate, empathic, helpful, kind, thoughtful, understanding). The six peripheral categories comprised attention-avoiding, gracious (doesn't take credit), honest (honest), likeable (likeable), not arrogant (not bigheaded, not arrogant), and plain (not flashy, plain). The remaining marginal categories (omitting exemplars for brevity) comprised arrogant $\uparrow$, confident, content, easygoing, embarrassed by praise, gentle*, good listener, inner confidence $\dagger$, insecure, polite, self-effacing, selfless, unassuming, unobtrusive, and unpretentious (where "*" signifies "only when duplicates excluded", and "†" signifies "only when duplicates included").

Exemplar priority. Exemplar frequency per category served as our primary index of prototypicality. However, our data also permitted the use of a subsidiary index, namely, the priority in which exemplars from each category were listed (i.e., which was written down earlier or later). Whereas exemplar frequency arguably reflects the chronic availability of exemplars pertaining to modesty, exemplar priority arguably reflects their temporary accessibility (Higgins, 1996; Tulving $\&$ Pearlstone, 1966). Accordingly, we used exemplar priority as a means of (a) confirming categorical differences in prototypicality, and (b) highlighting within-category variations in prototypicality.

To compute exemplar priority, we first noted the ordinal position in which participants listed each exemplar, and proceeded to organize these data by category. We then computed the 


\section{Prototypical Modesty}

median of these priority scores, in the UK and US samples separately, with duplicate exemplars included and excluded $\left(\mathrm{UK}_{\mathrm{INC}}=4, \mathrm{US}_{\mathrm{INC}}=4.5 ; \mathrm{UK}_{\mathrm{EXC}}=3, \mathrm{US}_{\mathrm{EXC}}=3\right)$. Next, we compared the ordinal position of each exemplar to the relevant median. ${ }^{3}$ If it fell above that median, then a score of +1 was assigned; if it fell below, a score of -1 was assigned; and if it equaled the median, a score of 0 was assigned. Subsequently, we summed these scores across all exemplars belonging to each of the 48 common categories, and divided each result by the number of exemplars in each category (to avoid mathematically confounding exemplar frequency with exemplar priority). Once derived, these indices of proportional exemplar priority $(P E P)$ per category were averaged across both samples to create a final index that varied between +1 and -1 .

Given that both exemplar frequency and exemplar priority were liable to reflect category prototypicality, we expected their respective indices to correlate positively. When duplicate exemplars were included, the correlation was positive but nonsignificant $(r=.22, p=.31)$. However, when duplicate exemplars were excluded, the correlation was both positive and significant $(r=.58, p<.005)$. This suggests that a more valid, or at least a more reliable, insight into the everyday concept of modesty may be afforded by excluding duplicate exemplars. ${ }^{4}$ Consequently, we took PEP per category into account only after excluding duplicates.

For central categories, mean PEP was .29, significantly greater than zero, $t(3)=4.25, p<$ .05 ; for peripheral categories, $.05, t(5)=.28, n s$; and for marginal categories -.16 , significantly less than zero, $t(12)=-3.02, p<.01$. Expressed in a different way, $100 \%$ of central categories, $50 \%$ of peripheral categories, and $15.4 \%$ of marginal categories had priority indices numerically above zero. Thus, the ordinal position of category clusters implied by priority scores mimicked that implied by frequency scores. Moreover, inspection of individual PEP per category scores hinted at the relative prototypicality of particular categories. In the central cluster, humble (.47) and shy (.32) both came out ahead of solicitous (.20) and not boastful (.17) - the same pattern observed for 


\section{Prototypical Modesty}

exemplar frequency scores. In the peripheral cluster, two, gracious (-.34) and plain (-.34), came out behind all other categories - again the same pattern observed as before. Arguably, the one other peripheral category with a negative PIP score, avoids attention (-.22), should be ranked beside them in terms of prototypicality. Finally, in the marginal cluster, only one category, unassuming, had a PEP score noticeably in excess of zero (.31); this might consequently be considered a backdoor candidate for inclusion in the peripheral cluster. The final clustering and internal ranking of categories is illustrated in Table 1.

\section{Discussion}

Several observations are worth making with respect to the categories found to characterize modesty, as well as with respect to their assignment to central, peripheral, and marginal clusters.

First, both humble and non-boastful emerged as central categories. This is consistent both with intuitive expectation and with some previous findings reported by Exline and Geyer (2004). In particular, these researchers found that descriptions or mentions of modesty (which they construed as also subsuming "not bragging") featured nearly half the time in everyday definitions of humility.

Second, another central category that emerged—solicitous — does not generally appear in dictionary definitions of modesty. This constitutes a possible point of disjunction between formal and informal conceptions of the personality trait. Also supporting this finding (in view of the humility/modesty overlap), Exline and Geyer (2004) found "kindness or caring towards others" was cited as often (56\%) as "refraining from bragging" (55\%) as a characteristic of humble people.

Third, most of the categories that typified modesty were seemingly positive (Table 1). Only a handful of apparent exceptions emerged, including shy (central), attention-avoiding (peripheral), and insecure (marginal). To confirm this intuition empirically, we had 33 University of Southampton graduate students $(70 \%$ female; Mean age $=28.3)$ complete a supplementary online rating task. These participants rated randomly selected exemplars belonging to each of the central, 
peripheral, and marginal categories along a relevant 6 -point bipolar scale $(1=$ negative, $6=$ positive). Our instructions read: “A positive [negative] description sounds good [bad]. It would be desirable [undesirable] to have it applied to you."

Results showed that modesty was construed positively (i.e., significantly above the scale midpoint), both overall, $M=4.44, t(32)=14.93, p<.001$, and at the level of central, peripheral, and marginal categories (corresponding $M \mathrm{~s}=4.82,4.50,4.68$; all $t \mathrm{~s}[32]>8.26$, all $p \mathrm{~s}<.001$ ). In addition, nearly all exemplars were individually rated as significantly positive (Table 2). The exceptions derived from the categories shy, unassuming, embarrassed by praise, and self-effacing (non-significant), and the categories insecure and unobtrusive (significantly negative). Thus, if modest people do have a perceived shortcoming, it might be undue diffidence. ${ }^{5}$ For completeness, we also had participants rate the concept "modesty" itself. As expected, its valence was also significantly positive, $M=4.82, t(32)=8.26, p<.001$.

Fourth, the categories typifying modesty seemingly pertained, not only to the public domain, but also to the private one. In particular, several categories arguably concerned inner qualities as much as they concerned outer qualities (central: humble; peripheral: unassuming; marginal: honest). Again, to confirm this intuition empirically, we had the same participants as above rate each of exemplars from central, peripheral, and marginal categories along a relevant 6point bipolar scale $(1=$ hidden, 6 = observable $)$. Our instructions read: “A hidden [observable] description refers to the private [public] aspects of a person. It has to do with how people are inside their mind [behave around others]."

Results showed that modesty was rated more observable than hidden (i.e., significantly above the scale midpoint), both overall, $M=4.20, t(32)=7.48, p<.001$, and at the level of central, peripheral, and marginal categories respectively (corresponding $M \mathrm{~s}=4.20,4.23,4.48$; all $t \mathrm{~s}[32]>$ 5.93, all $p \mathrm{~s}<.001)$. However, ratings of the observability of modesty exemplars were nonetheless 
significantly lower than earlier ratings of the positivity of those exemplars, both overall, $t(32)=$ $2.34, p<.05$, and for both central categories, $t(32)=2.56, p<.01$, and peripheral categories, $t(32)$ $=3.54, p<.001$, but not marginal categories, $t(32)=-.24, p=.81$. In addition, exemplars from several key categories were rated individually as being no less hidden (i.e., private and intrapersonal) than they were observable (i.e., public and interpersonal). In particular (Table 2), ratings of exemplars from the single most prototypical category humble (central)—and from the other categories honest, attention-avoiding, gracious (peripheral), unassuming, self-effacing, and selfless (marginal) — did not differ from the scale midpoint. For completeness, we also had participants rate the concept "modesty" itself. Tellingly, they rated it as non-significantly more hidden than observable $(M=3.39, t[32]=-.47, p=.64)$.

It should also be emphasized that, both because concrete exemplars of trait categories were rated and because the traits exemplified involved dispositions to exhibit behaviors (Matthews, Deary, \& Whiteman, 2003; Ryle, 1949), one would have expected a priori that most exemplars would be rated as at least as observable as hidden. Hence, our assessment of positive departures from the scale midpoint was a liberal test of the relative observability of exemplars and their corresponding categories. Yet, for several key categories, significance was nonetheless not attained. Moreover, if we had applied a conservative test - for example, if we had assessed positive departures from the midpoint of the upper half of the scale (4.75) - then most mean ratings of observability would have fallen significantly below it (at $p<.01$ ).

Hence, an unpartisan inference to be drawn from these findings is that, although the prototypical concept of modesty mostly encompasses phenomena that are broadly public and interpersonal, it nonetheless encompasses some phenomena that are about as private and intrapersonal as could be expected. Hence, modesty is not — as popularly construed - either 
intrinsically public (Cialdini et al. 1998) or intrinsically private (Sedikides et al., 2007), but a mixture of the two (Exline, Campbell et al., 2004).

\section{Study 2}

\section{Overview}

In Study 1, we used two indices of prototypicality — category frequency and priority — to sort categories exemplifying the concept of modesty into three higher-order clusters of increasing prototypicality: marginal, peripheral, and central. In Study 2, we sought to confirm the validity of these ordinal distinctions. To this end, we gave participants an impression formation task, in which they rated (amongst other things) the modesty of several hypothetical persons. Each hypothetical person was described in terms of multiple exemplars derived from one of the three ordinal clusters (and, for completeness, from an additional cluster of remote exemplars). We predicted that the ordinal pattern of ratings would map on precisely to the ordinal pattern of prototypical clusters.

$$
\text { Method }
$$

\section{Participants}

Fifty University of Southampton undergraduate students $\left(\mathrm{M}_{\mathrm{AGE}}=25.9 ; \mathrm{SD}_{\mathrm{AGE}}=9.8 ; 62 \%\right.$ female) participated in return for partial course credit.

\section{Procedure}

All participants were issued a deck of 16 cardboard cards $(6 \mathrm{~cm} \mathrm{X} 4 \mathrm{~cm})$ together with an A4-sized booklet. Each card featured four exemplars of the categories earlier deemed to be more or less prototypical of modesty (as opposed to the category labels). Four different sets, each containing four cards, displayed a random selection of exemplars drawn from each of four clusters: central, peripheral, marginal, and remote. For example, one card with central exemplars read doesn't show off, puts others before self, quiet, and humble; another card with peripheral exemplars read approachable, not full of themselves, not flashy, honest; another with marginal exemplars read 
selfless, confident, down-to-earth, easygoing; and another with remote exemplars read moral, tactful, easily embarrassed, puts themselves down.

Participants began by shuffling their deck of cards. They then took the first card from the deck and inspected the exemplars listed. Next, they opened the first page of the booklet and answered six questions relating to their impression of a hypothetical person that those exemplars described. The key question read, "How MODEST [capitals in original] is the person described on the card?" $(1=$ Not at all, 7 = Very much so $)$. For half the participants, this key question appeared in third position, for the other half, in sixth. The five other filler questions, identical in format, featured descriptors pertaining to the "Big Five" personality traits (Ashton, Lee, \& Goldberg, 2004). After answering the questions, participants then noted the number, 1 to 16 , printed on the reverse of the card, and wrote it at the top of the first page (thereby correlating the particular card inspected with answers given). Participants repeated this procedure for each of the 15 remaining cards and booklet pages. The study took 7-10 minutes to complete. Thereafter, participants were debriefed, thanked, and dismissed.

\section{Results and Discussion}

After averaging ratings of modesty across the four cards representing each of the four prototypical clusters, we conducted planned contrasts to test for the predicted ordinal pattern: a rise in mean modesty ratings, from the remote cluster, through the marginal, peripheral, and central clusters in succession. As predicted, a significant linear effect emerged, $F(1,49)=192.90, p<$ .0001 (Figure 1). This was accompanied by a smaller quadratic effect, $F(1,49)=5.56, p<.02$. A set of follow-up pairwise comparisons confirmed that ratings for each successive cluster differed significantly from its predecessor. In particular, the central cluster yielded significantly greater modesty ratings than the peripheral one, $t(49)=3.15, p<.01$; the peripheral cluster yielded significantly greater modesty ratings than the marginal one, $t(49)=4.55, p<.001$; and the marginal 
cluster yielded significantly greater modesty ratings than the remote one, $t(49)=5.84, p<.001$. Nonetheless, all clusters yielded modesty ratings significantly above the midpoint of the scale (all $p \mathrm{~s}<.001)$, given that they had already been selected as representing common components of modesty across UK and US samples. Finally, no significant effects of question position (i.e., third versus last) emerged, $F<1$.

\section{Study 3}

\section{Overview}

In Study 2, we confirmed that, when ascribed to hypothetical targets, the exemplars characterizing different clusters of modesty-related categories—specifically, central, peripheral, marginal, and remote - elicited mean modesty ratings that corresponded neatly to the predicted ordinal pattern implied by Study 1. In Study 3, we sought to conceptually replicate this effect using a relatively large and diverse internet sample (as opposed to a relatively small and homogenous university one) that predominantly featured participants from the US (as opposed to from the UK only). However, Study 3 had a further purpose: to show that the distinctions between clusters would be apparent, not only at the level of self-reported ratings, but also a more automatic or implicit cognitive level (Bassili, 2001; Fazio, 1995; Greenwald \& Banaji, 1995). To this end, we assessed not only which exemplars participants regarded as more diagnostic of modesty, but also the speed with which they made these determinations. In particular, we predicted, not only that person $\mathrm{X}$ would be more often deemed more modest than person $\mathrm{Y}$, to the degree that $\mathrm{X}$ was described by a more prototypical exemplar than $\mathrm{Y}$, but also that $\mathrm{X}$ would be more quickly deemed more modest than Y, for the same reason.

\section{Method}

\section{Participants}




\section{Prototypical Modesty}

All 175 participants $\left(\mathrm{M}_{\mathrm{AGE}}=27.1 ; \mathrm{SD}_{\mathrm{AGE}}=11.1 ; 73 \%\right.$ female $)$ were recruited via, and took part over, the internet. Their countries of residence were as follows: US (54.3\%), UK (29.5\%), Canada $(8.7 \%)$, other countries (7.5\%). Participants were instructed not to participate unless fluent at English. Participation was entirely voluntary. The program running the study was written in JAVA by the second author, hosted by http://mindstudies.psy.soton.ac.uk, and advertised on prominent online research websites such as $h t t p: / / w w w . s o c i a l p s y c h o l o g y . o r g$, http://www.onlinepsychresearch.co.uk, and http://psych.hanover.edu/research/exponnet.html. No two participants shared the same IP address.

\section{Procedure}

Via a digital interface, participants were repeatedly shown different pairs of "cards" labeled A and B. Each card featured one exemplar describing a corresponding hypothetical person. Both cards were initially presented for five seconds. At this point, a small button labeled click appeared centrally below. When clicked, this button disappeared, to be instantly replaced by two further buttons labeled Person A and Person B, placed equidistantly to the left and right. In addition, halfway between the pair of cards above, and in the centre of the screen, a question appeared along with the buttons. The question took the form Who is more [ADJECTIVE]? where the capitalized adjective was either MODEST or one of several other filler adjectives. Participants repeatedly judged, by moving the mouse to click on one of the buttons, which of the two persons described by the exemplars, A or B, was the more ADJECTIVE. Unbeknownst to them, not only was their judgment recorded, but also the time it took them to report it. The click button was placed equidistantly from the two buttons to reduce variability in response times.

When participants clicked either of the two buttons, both disappeared and were replaced by the original click button. When this was clicked, a new question appeared, together with the two lateral buttons for Person A and Person B. The procedure was repeated until all six questions 
associated with each pair of cards had been presented. The third question in the sequence featured the key adjective MODEST (the order factor having had no impact previously); the other five questions featured adjectives derived from the "Big Five" (as in Study 2).

In total, participants completed 18 practice trials (corresponding to 3 pairs of cards, featuring non-modesty exemplars), and 144 experimental trials (corresponding to 24 pairs of cards, featuring modesty exemplars). Participants were permitted a short break halfway through the experimental trials.

Design

As in Study 2, exemplars were drawn from each of the four prototypical clusters: central $(\mathrm{C})$, peripheral $(\mathrm{P})$, marginal $(\mathrm{M})$, and remote $(\mathrm{R})$. Each pair of cards featured exemplars from nonidentical clusters, resulting in six types of pairs, each of which appeared four times: (C vs. P), (C vs. M), (C vs. R), (P vs. M), (P vs. R), and (M vs. R). Exemplars were randomly selected from corresponding clusters (with replacement, given that the clusters naturally happened to contain different numbers of exemplars). In addition, which person, A or B, was ascribed which exemplar, was also randomized.

If the prototypicality estimates arrived at in Study 1 were correct - that is, if $\mathrm{C}>\mathrm{P}>\mathrm{M}>\mathrm{R}$, where ">" means "more prototypical than"- then some of the participants" decisions, as to which person, A or B, was more modest depending on the exemplar ascribed to them, should have been clearer and easier than others. In particular, decisions should have been clearest and easiest when the exemplars came from the prototypically most distant cluster (C vs. R); intermediately clear and easy when they came from the two prototypically nearby clusters (C vs. M; P vs. R); and least clear and easy when they came from the three prototypically adjacent clusters (C vs. P; P vs. M; M vs. $\mathrm{R})$. 
Consequently, we made two predictions. First, we predicted that participants would judge that person, $\mathrm{A}$ or $\mathrm{B}$, who had been ascribed the more prototypically modest exemplar (according to Study 1) as being the more modest, and that this would happen most frequently when comparing exemplars from distant clusters (C vs. R), intermediately frequently when comparing exemplars from nearby clusters (C vs. M; P vs. R), and least frequently when comparing exemplars from adjacent clusters (C vs. P; P vs. M; M vs. R). Second, we predicted that this judgment, especially when correct, would also be made more quickly when comparing exemplars from distant clusters, intermediately quickly when comparing exemplars from adjacent clusters, and least quickly when comparing exemplars from nearby clusters.

\section{Results and Discussion}

\section{Data Reduction}

On each trial, we recorded the choice of exemplar made, and the time taken to make it. Response times less than $350 \mathrm{~ms}$ or greater than $10,000 \mathrm{~ms}(<3 \%)$ were respectively recoded to those boundary values (cf. Greenwald, McGhee, \& Schwartz, 1998). Exemplar choices and response times were then averaged across the three types of cluster pairs: distant, nearby, and adjacent. At this point, six participants with suspiciously extreme aggregate scores were excluded. All other aggregate scores were then logarithmically transformed to base $e$ to further normalize their distributions and homogenize their variances.

\section{Modesty Judgments: Choices Made}

We conducted a planned linear contrast to test for the predicted ordinal pattern: a stepwise rise in the frequency with which the more prototypically modest exemplar was chosen — from pairs of adjacent clusters, through pairs of nearby clusters, to the pair of distant clusters. As predicted, a significant linear effect emerged, $F(1,168)=19.60, p<.0005$, unaccompanied by any quadratic effect, $F(1,169)<1$ (see Figure 2). A set of follow-up pairwise comparisons examined whether 
the frequency of prototypical choices differed significantly for each successive cluster pair. The adjacent cluster pair yielded a significantly lower frequency $(58 \%)$ than the nearby pair $(65 \%), F(1$, $168)=12.60, p<.0005$, although the nearby cluster pair yielded only a directionally lower frequency than the distant pair $(68 \%), F(1,168)=2.03, p=.11$.

That the percentages above are not higher is perhaps part and parcel of the conceptual fuzziness involved: precise discrimination cannot be expected given the everyday concept lacks necessary or sufficient defining criteria. What matters for present purposes is an unqualified linear trend that emerges in the percentage of "correct" discriminations made as those discriminations are based on progressively greater disparities in prototypicality.

\section{Modesty Judgments: Response Speed}

Once again, we conducted a planned linear contrast to test for the predicted ordinal pattern: a rise in the speed with which an exemplar was chosen - from pairs of adjacent clusters, through pairs of nearby clusters, to the pair of distant clusters. And once again, a significant linear effect emerged, $F(1,168)=8.66, p<.005$, unaccompanied by any quadratic effect, $F(1,168)<1$ (Figure 3). A set of follow-up pairwise comparisons examined whether choice speed differed significantly for each successive cluster pair. Choices were made marginally faster for the adjacent cluster pair than for the nearby pair, $F(1,168)=3.46, p=.07$, but only directionally faster for the nearby cluster pair than for the distant pair, $t(1,168)=1.87, p=.17$.

The response speeds above were derived both from trials where participants chose the more prototypical exemplar (62\% overall) and from trials where they chose the less prototypical exemplar (38\% overall). However, one might expect the predicted pattern of response speed to be stronger for the former "correct" trials — where the more prototypical exemplar was identifiedthan for the latter "incorrect" ones - where it was misidentified. We would argue as follows. Suppose, for the sake of argument, that the prototypical categories arrived at in Study 1 are broadly 


\section{Prototypical Modesty}

correct (as the results from Study 2, and from Study 3 so far, suggest). If so, then "correct" responses would tend to reflect the influence of a consistent, shared, and intelligible everyday concept (i.e., modesty), whereas "incorrect" ones would not—-tending instead to reflect inconsistent, idiosyncratic, or confounded concepts. And if this were the case, then one would further expect the speed of "correct" responses to vary more in accordance with prototypical disparities than the speed of "incorrect" responses, because the former response would be made more with the everyday concept of modesty in mind than the latter.

This expectation was borne out. A strong linear effect emerged for the "correct" trials, $F(1$, $165)=11.74, p<.001$, unaccompanied by any quadratic effect, $F(1,165)<1 .{ }^{6}$ In addition, choices were now made significantly faster for the adjacent cluster pair than for the nearby pair, $F(1,165)$, $p<.05$, albeit again only directionally faster for the nearby cluster pair than for the distant pair, $F(1,165), p=.22$. In contrast, no significant linear effect, $F(1,126)=2.28, p=.13$, nor any quadratic effect, $F(1,126)<1$, emerged for the "error" trials, nor were any of the follow-up pairwise comparisons significant. This disparity arguably provides indirect support for the authenticity of the prototypical categories arrived at in Study 1.

In all, Study 3 showed that the prototypical categories derived from Study 1 can be readily differentiated, not only at the level of explicit judgment (choices of exemplar), but also at the level of implicit processing (time taken to make those choices). All the explicitly predicted linear trends emerged, unqualified by any quadratic effects. The occasional "rough edges" observed in the data at the level of pairwise comparisons may be attributable either to inattention fostered by the protracted and repetitive nature of the study, to our inability to ensure that all our remote participants responded conscientiously, or to the inherently fuzzy nature of the everyday concept of modesty itself. 
What does this research tell us about how people commonly construe modesty? Three key points can be distilled.

First, the majority of prototypical categories identified were favorable: everyday modesty, as a personality trait, is generally regarded more positively than negatively. Indeed, exemplars from the (four) central and (six) peripheral categories were rated individually as significantly positive, with the exception of two rated neutrally; and exemplars from the (thirteen) marginal categories were rated individually as significantly positive, with the exception of two rated significantly negatively. Overall, these results fit well with previous research showing that modest individuals are generally well-liked and favorably judged by peers and colleagues (Exline, Single, Lobel, \& Geyer, 2004; Heatherton \& Vohs, 2000; Powers \& Zuroff, 1988; Schlenker \& Leary, 1982; Wosinska, Dabul, Whetstone-Dion, \& Cialdini, 1996). If modest individuals suffer from a perceived shortcoming, however, it might be that they lack social projection: they are seen as relatively shy, unobtrusive, self-effacing, and unassuming. Still, this shortcoming hardly qualifies as a major vice. Moreover, even if they are seen as insecure, they are also, by way of compensation, seen as confident, suggesting that the reduced propensity of modest individuals to self-enhance is construed both as a sign of fragile and of secure self-esteem (Kernis \& Paradise, 2002). Thus, like its sister concept humility (Peterson \& Seligman, 2004; Tangney, 2000), modesty may be more positively regarded in Western culture than is commonly believed (Exline \& Geyer, 2004; Sedikides et al., 2007).

A second noteworthy finding is that the prototypical categories identified are not only public in character but also private. Several key categories (e.g., humble, honest, gracious) are built out of exemplars that are no less linked to underlying psychological processes than to overt public behavior. Thus, everyday modesty is neither all about social deference alone (Shalit, 1999), nor all about moderate self-perception alone (Sedikides et al., 2007), but about a combination of the two. 
A third finding is more intriguing. People evidently regard a prosocial orientation as an intrinsic as opposed to incidental feature of modesty. In terms of central categories, modest people were primarily described, not just as humble, shy, and not boastful, but also as solicitous. Exemplars subsumed by this final category included such glowing descriptors as "caring," "kind," "thoughtful," “considerate," "empathic," "understanding," and "helpful." Also, in terms of peripheral categories, modest people were also described, not only as not arrogant, avoiding attention, plain, and gracious, but also as honest and likeable. Finally, most of the marginal categories had a distinctively prosocial flavor. Clearly, modest people are seen, despite their lack of social projection, as highly agreeable. Moreover, they are not only seen as highly agreeable in a superficial and general sense - in terms of possessing admirable or attractive qualities to be appreciated — but also in a deeper and specific sense — in terms of being both willing and able to assist other people in times of need. Hence, current theoretical definitions of modesty should perhaps be extended, even at the cost of some rigor, to take account of this popular attribution of understated agreeableness and inherent prosociality. A further reason to do so is that other research already shows both subjective and objective links between indices of modesty and a prosocial orientation (Sedikides et al., 2007). For example, Robinson, Johnson, and Shields (1995) found that people who gave a balanced self-presentation (e.g., who modestly referred to their vices as well as virtues) were subjectively regarded as more likeable, honest, and authentic than people who gave either a self-deprecating or self-enhancing self-presentation. Moreover, Ehrenberg, Hunter, and Elterman (1996) found that divorced couples who adopted a cooperative as opposed to antagonistic approach to the sharing of parental duties were objectively more modest about themselves and less arrogant in their attitudes towards parenting.

Interestingly, research on the basic dimensions of personality also implies that there is more to being prosocial than merely being pleasant: it is possible to be overtly amiable without being 


\section{Prototypical Modesty}

28

morally decent, and morally decent without being overtly amiable (Ashton \& Lee, 2005). ${ }^{7} \mathrm{We}$ suggest that modest people are perceived as, and probably actually are, high in both superficial agreeableness and underlying honesty-humility. That would explain, for example, why modesty is both defined in the dictionary and perceived by the populace as a phenomenon with both public and private facets.

Moreover, modest people are arguably the opposite of narcissists, who not only selfenhance privately to an undue degree, but also publicly exploit other people for egotistical purposes (Rhodewalt \& Morf, 2004; Sedikides, Campbell, Reeder, Elliot, \& Gregg, 2002). This observation suggests some interesting hypotheses. For example, if narcissists have high explicit but low implicit self-esteem, possibly reflective of ego-fragility (Gregg \& Sedikides, 2007; Jordan, Spencer, Zanna, Hoshino-Browne, \& Correll, 2003; Zeigler-Hill, 2006), then one might expect modest people to have low explicit but high implicit self-esteem, possibly reflective of ego-security (although see Schröder-Abé, Rudolph, \& Schütz, 2007). In addition, consider a simple game in experimental economics: dictator (Bolton, Katok, \& Zwick, 1998). One player is given a sum that she must allocate in any proportion she wishes to herself and another player (e.g., $100 \%$ vs. $0 \% ; 75 \%$ vs. $25 \% ; 50 \%$ vs. $50 \%$ ). Most players share part of the sum with the other player even though they could keep it all themselves, thereby confounding homo economicus. However, individual differences in personality may also have a bearing on the allocation; specifically, modest people may tend to share more equitably, narcissists more inequitably. Finally, take garden-variety selfesteem — which can be construed as a dispositional form of self-enhancement (Sedikides \& Gregg, 2003, in press). Low self-esteem has traditionally been touted as a key contributor to antisocial behavior (Mecca, Smelser, \& Vasconcellos, 1989). Although some empirical studies bear out this view (Donnellan, Trzesniewski, Robins, Moffitt, \& Caspi, 2005; Trzesniewski, Donnellan, Caspi, Moffitt, Robins, \& Poultin, 2006), others do not (Baumeister et al., 2003). Indeed, some research 
finds that people high in self-esteem are more likely to aggress (Baumeister, Smart, \& Boden, 1996), especially when their self-esteem is over-inflated (Bushman \& Baumeister, 1998) or unstable (Kernis, Granneman, \& Barclay, 1989). So, by a process of elimination, the most prosocial, or least antisocial, of all people are those who self-enhance intermediately rather than too much or too little - that is, modest people. The current findings on how modest people are characteristically construed are consistent with this contention.

To sum up, the picture of modest people to emerge from our empirical survey is as follows: they are interpersonally pleasant while being socially unobtrusive; they are disinclined either to overt bragging or covert arrogance; and they are genuinely concerned about the people around them. The non-obvious emergence of the last feature from our prototype analysis suggests that current definitions of modesty might benefit from some broadening; and it also implies intriguing possibilities for future empirical research. 
Prototypical Modesty

References

Ashton, M. C., \& Lee, K. (2005). Honesty-Humility, the Big Five, and the Five Factor Model. Journal of Personality, 73, 1321-1353.

Ashton, M. C., Lee, K., \& Goldberg, L. R. (2004). A hierarchical analysis of 1,710 English personality-descriptive adjectives. Journal of Personality and Social Psychology, 87, $707-721$

Ashton, M. C., Lee, K., Perugini, M., Szarota, P., De Vries, R. E., Di Blas, L., et al. (2004). A six-factor structure of personality-descriptive adjectives: Solutions from psycholexical studies in seven languages. Journal of Personality and Social Psychology, 86, 356-366.

Bassili, J. N. (2001). Cognitive indices of social information processing. In A. Tesser \& N. Schwarz (Eds.), Blackwell handbook of social psychology: Intraindividual processes (Vol. 1, pp. 68-88). Oxford, England: Blackwell.

Baumeister, R. F., Campbell, J. D., Krueger, J. I., \& Vohs, K. D. (2003). Does high self-esteem cause better performance, interpersonal success, happiness or healthier lifestyles? Psychological Science in the Public Interest, 4, 1-44.

Baumeister, R. F., Smart, L., \& Boden, J. M. (1996). Relation of threatened egotism to violence and aggression: The dark side of high self-esteem. Psychological Review, 103, 5-33.

Bolton, G. E., Katok, E., \& Zwick, R. (1998). Dictator game giving: Rules of fairness versus acts of kindness. International Journal of Game Theory, 27, 269-299.

Bond, M. H., Kwan, V. S. Y., \& Li, C. (2000). Decomposing a sense of superiority: The differential social impact of self-regard and regard-for-others. Journal of Research in Personality, 34, 537-553.

Bond, M., H., Leung, K., \& Wan, K. C. (1982). The social impact of self-effacing attributions: The Chinese case. Journal of Social Psychology, 118, 157-166. 
Broughton, R. (1984). A prototype strategy for construction of personality scales. Journal of Personality and Social Psychology, 47, 1334-1346.

Bushman, B. J., \& Baumeister, R. F. (1998). Threatened egotism, narcissism, self-esteem, and direct and displaced aggression: Does self-love or self-hate lead to violence? Journal of Personality and Social Psychology, 75, 219-229.

Buss, D.M., \& Craik, K. H. (1985). Why not measure that trait? Alternative criteria for identifying important dispositions. Journal of Personality and Social Psychology, 48, 934-946.

Chen, S. X., Bond, M. H., \& Tang, D. (2006). Behavioral Manifestations of Modesty: Do SelfConstruals Work Differently in Different Collectivistic Cultures? Unpublished manuscript, Beijing Normal University, China.

Cialdini, R. B., Wosinska, W. Dabul, A. J., Whestone-Dion, R., \& Heszen, I. (1998). When role salience leads to social role rejection: Modest self-presentation among women and men in two cultures. Personality and Social Psychology Bulletin, 24, 473-481.

Crittenden, K. S. (1991). Asian self-effacement or feminine modesty? Attributional patterns of women university students in Taiwan. Gender and Society, 5, 98-117.

Cronbach, L. J., \& Meehl, P. E. (1955). Construct validity in psychological tests. Psychological Bulletin, 52, 281-302.

Donnellan, M. B., Trzesniewski, K. H., Robins, R. W., Moffitt, T. E., \& Caspi, A. (2005). Exploring the link between self-esteem and externalizing problems: Low self-esteem is linked to antisocial behavior and delinquency. Psychological Science, 16, 328-335.

Dunning, D., Heath, C., \& Suls, J. M. (2004). Flawed self-assessment. Psychological Science in the Public Interest, 5, 69-106. 
Eagly, A. H., \& Acksen, B. A. (1971). The effect of expecting to be evaluated on change toward favorable and unfavorable information about oneself. Sociometry, 34, 411-422.

Ehrenberg, M. F., Hunter, M. A., \& Elterman, M. F. (1996). Shared parenting agreements after marital separation: The roles of empathy and narcissism. Journal of Consulting and Clinical Psychology, 64, 808-818.

Exline, J. J., Campbell, W. K., Baumeister, R. F., Joiner, T., \& Krueger, J. (2004). Humility and modesty. In C. Peterson \& M. Seligman (Eds.), The Values In Action (VIA) classification of strengths. Cincinnati, OH: Values in Action Institute.

Exline, J. J, \& Geyer, A. L. (2004). Perceptions of humility: A preliminary study. Self and Identity, 3, 95-114.

Exline, J. J., Single, P. B., Lobel, M., \& Geyer, A. L. (2004). Glowing praise and the envious gaze: Social dilemmas surrounding the public recognition of achievement. Basic and Applied Social Psychology, 26, 119-130.

Fazio, R. H. (1995). Attitudes as object-evaluation associations: Determinants, consequences, and correlates of attitude accessibility. In R. E. Petty \& J. A. Krosnick (Eds.), Attitude strength: Antecedents and consequences (pp. 247-282). Hillsdale, NJ: Erlbaum.

Gilbert, D. (2006). Stumbling on happiness. New York: Knopf.

Greenwald, A. G., \& Banaji, M. R. (1995). Implicit social cognition: Attitudes, self-esteem, and stereotypes. Psychological Review, 102, 4-27.

Greenwald, A. G., McGhee, D. E., \& Schwartz, J. K. L. (1998). Measuring individual differences in implicit cognition: The implicit association test. Journal of Personality and Social Psychology, 74, 1464-1480.

Gregg, A. P., \& Sedikides, C. (2007). Narcissism and Implicit Self-Esteem: Rethinking the Link. Unpublished manuscript, University of Southampton. 
Gu, Y. (1990). Politness phenomena in modern Chinese. Journal of Pragmatics, 14, 237-257.

Guralnik, D. B. (Ed.). (1984). Webster's new world dictionary ( $2^{\text {nd }}$ college ed.). New York: Warner Books.

Hassebrauck, M. (1997). Cognitions of relationship quality: A prototype analysis of their structure and consequences. Personal Relationships, 4, 163-185.

Heatherton, T. F., \& Vohs, K. D. (2000). Interpersonal evaluations following threats to self: Role of self-esteem. Journal of Personality and Social Psychology, 78, 725-736.

Heine, S. J., Lehman, D. R., Markus, H. R., \& Kitayama, S. (1999). Is there a universal need for positive self-regard? Psychological Review, 106, 766-794.

Higgins, E. T. (1996). Knowledge activation: Accessibility, applicability, and salience. In E. T. Higgins \& A. W. Kruglanski (Eds.), Social psychology: Handbook of basic principles (pp. 133-168). New York: The Guilford Press.

Jones, E. E., \& Wortman, C. (1973). Ingratiation: An attributional approach. Morristown, NJ: General Learning Press.

Jordan, C. H., Spencer, S. J., Zanna, M. P., Hoshino-Browne, E., \& Correll, J. (2003). Implicit selfesteem, explicit self-esteem and defensiveness. Journal of Personality and Social Psychology, 85, 969-978.

Kernis, M. H., Granneman, B. D., \& Barclay, L. C. (1989). Stability and level of self-esteem as predictors of anger arousal and hostility. Journal of Personality and Social Psychology, $56,1013-1022$.

Kernis, M. H., \& Paradise, A. W. (2002). Distinguishing between secure and fragile forms of high self-esteem. In E. L. Deci \& R. M. Ryan (Eds.), Handbook of self-determination research (pp. 339-360). Rochester, NY: University of Rochester Press.

Matthews, G., Deary, I. J., \& Whiteman, M. C. (2003). Personality Traits (2nd Ed.). Cambridge: 
Cambridge University Press.

McCrae, R. R., \& Costa, P. T., Jr. (1997). Personality trait structure as a human universal. American Psychologist, 52, 509-516.

Mecca, A. M., Smelser, N. J., \& Vasconcellos, J. (1989). The social importance of self-esteem. Berkeley, CA: University of California Press.

Mish, F. C. (Ed.). (1991). Webster's ninth new collegiate dictionary. Springfield, MA: MerriamWebster Inc., Publishers.

Neff, K. D. (2003). Self-compassion: An alternative conceptualization of a healthy attitude toward oneself. Self and Identity, 2, 85-102.

Nietzsche, F. (1887/1989). On the genealogy of morals and ecce homo. New York: Vintage Books.

Pearsall, J. (Ed.). (2001). The new Oxford dictionary of English. Oxford: Oxford University Press.

Peterson, C., Park, N., \& Seligman, M. E. P. (2006). Greater strengths of character and recovery from illness. The Journal of Positive Psychology, 1, 17-26.

Peterson, C., \& Seligman, M. E. P. (2004). Character strengths and virtues: A handbook and classification. Washington, DC: American Psychological Association.

Petty, R. E., \& Wegener, D. T. (1998). Attitude change: Multiple roles for persuasion variables. In D. Gilbert, S. Fiske, \& G. Lindzey (Eds.), The handbook of social psychology (4th ed., pp. 323-390). New York: McGraw-Hill.

Popper, K. (1959). The Logic of Scientific Discovery. Hutchinson: London.

Powers, T. A., \& Zuroff, D. C. (1988). Interpersonal consequences of overt self-criticism: A comparison with neutral and self-enhancing presentations of self. Journal of Personality and Social Psychology, 54, 1054-1062. 
Rhodewalt, F., \& Morf, C. C. (2004). Reflections in troubled waters: Narcissism and the vicissitudes of an interpersonally contextualized self. In A. Tesser, J. V. Wood, \& D. A. Stapel (Eds.), On building, defending and regulation the self: A psychological perspective (pp. 127-151). New York, NY: Psychology Press.

Robinson, M. D., Johnson, J. T., \& Shields, S. A. (1995). On the advantages of modesty: The benefits of a balanced self-presentation. Communication Research, 22, 575-591.

Rosch, E. (1978). Principles of categorization. In E. Rosch \& B. B. Lloyd (Eds.), Cognition and categorization (pp. 27-48). Hillsdale, NJ: Erlbaum.

Ryle, G. (1949). The concept of mind. Chicago: University of Chicago Press.

Schlenker, B. R. (1980). Impression management: The self-concept, social identity, and interpersonal relations. Monterey, CA: Brooks/Cole.

Schlenker, B. R., \& Leary, M. R. (1982). Audiences' reactions to self-enhancing, selfdenigrating, and accurate self-presentations. Journal of Experimental Social Psychology, $18,89-104$.

Schröder-Abé, M., Rudolph, A. \& Schütz, A. (2007). High implicit self-esteem is not necessarily advantageous: Discrepancies between explicit and implicit self-esteem and their relationship with anger expression and psychological health. European Journal of Personality, 21, 319-339.

Sedikides, C., Campbell, W. K., Reeder, G., Elliot, A. J., \& Gregg, A. P. (2002). Do others bring out the worst in narcissists?; The "Others Exist for Me" illusion. In Y. Kashima, M. Foddy, \& M. Platow (Eds.), Self and identity: Personal, social, and symbolic (pp. 103123). Mahwah, NJ: Lawrence Erlbaum Associates.

Sedikides, C., Gaertner, L., \& Toguchi, Y. (2003). Pancultural self-enhancement. Journal of Personality and Social Psychology, 84, 60-70. 


\section{Prototypical Modesty}

Sedikides, C., \& Gregg, A. P. (2003). Portraits of the self. In M. A. Hogg \& J. Cooper (Eds.), Sage handbook of social psychology (pp. 110-138). London: Sage Publications.

Sedikides, C., \& Gregg, A. P. (in press). Self-enhancement: Food for thought. Perspectives on Psychological Science.

Sedikides, C., Gregg, A. P., \& Hart, C. M. (2007). The importance of being modest. In C. Sedikides \& S. Spencer (Eds.), The self: Frontiers in social psychology (pp. 163-184). New York, NY: Psychology Press.

Shalit, W. (1999). A return to modesty: Discovering the lost virtue. NY: Touchstone.

Smith, E. E., \& Medin, D. L. (1981). Categories and concepts. Cambridge, MA: Harvard University Press.

Tangney, J. P. (2000). Humility: Theoretical perspectives, empirical findings, and directions for future research. Journal of Social and Clinical Psychology, 19, 70-82.

Tice, D. M., Butler, J. L., Muraven, M. B., \& Stillwell, A. M. (1995). When modesty prevails: Differential favorability of self-presentation to friends and strangers. Journal of Personality and Social Psychology, 69, 1120-1138.

Trzesniewski, K. H., Donnellan, M. B., Caspi, A., Moffitt, T. E., Robins, R. W., \& Poultin, R. (2006). Adolescent low self-esteem is a risk factor for adult poor health, criminal behavior, and limited economic prospects. Developmental Psychology, 42, 381-390.

Tulving, E. \& Pearlstone, Z. (1966). Availability versus accessibility of information in memory for words. Journal of Verbal Learning and Verbal Behavior, 5, 381-91.

Wegener, D. T., \& Fabrigar, L. R. (2004). Constructing and evaluating quantitative measures for social psychological research: Conceptual challenges and methodological solutions. In C. Sansone, C. C. Morf, \& A. T. Panter (Eds.), The SAGE handbook of methods in social psychology (pp. 145-172). New York: Sage. 
Wittgenstein, L. (1953/1967). Philosophical Investigations (3rd ed., trans. G. E. M. Anscombe). Oxford: Blackwell.

Wosinska, W., Dabul, A. J., Whetstone-Dion, R., \& Cialdini, R. B. (1996). Self-presentational responses to success in the organization: The costs and benefits of modesty. Basic and Applied Social Psychology, 18, 229-242.

Zeigler-Hill, V. (2006). Discrepancies between implicit and explicit self-esteem: Implications for narcissism and self-esteem instability. Journal of Personality, 74, 119-143. 
Author Note

Aiden P. Gregg, Claire Hart, and Constantine Sedikides, School of Psychology, University of Southampton, England, UK; Madoka Kumashiro, Goldsmiths College, University of London, England, UK.

This research was supported by Economic and Social Research Council Grant RES-000-230331. We thank Elle Boag, Joanna Lait, and Claire Wade for their valuable assistance with data collection and coding. Correspondence concerning this article should be addressed to Aiden P. Gregg, Center for Research on Self and Identity, School of Psychology, University of Southampton, Southampton SO17 1BJ, England, UK; email: aiden@soton.ac.uk. 


\section{Footnotes}

${ }^{1}$ The authors of this article, being modest themselves, would like to assure readers that this is purely a hypothetical example.

${ }^{2}$ Note, too, that although one can be humbled or humiliated, one cannot be "modest-ed" or "modest-ified". This suggests another point of divergence between the two concepts.

${ }^{3}$ One disadvantage of computing priority in this way is that, in this case, the more numerous exemplars generated by more fluent participants will emerge as relatively less prior, and the less numerous exemplars generated by less fluent participants as relatively more prior. To sidestep this problem, priority might instead be computed by comparing each exemplar's average ordinal position to each participants' median rather than to the sample's grand median. However, in this case, the more numerous exemplars generated by more earnest participants would emerge as relatively less prior, and the less numerous exemplars generated by less earnest participants as relatively more prior. Thus, both methods of computation have an advantage and disadvantage the other lacks. However, regardless of which method is used, the results should roughly converge, given sufficient sample size. Both methods also produce more stable results when applied to exemplars that occur with reasonable frequency (as is the case for the 23 or 24 final categories). ${ }^{4}$ The fact that including duplicate exemplars placed the paradoxical category arrogant within the marginal prototype of modesty may be further grounds for favoring their exclusion.

${ }^{5}$ It might seem that all these categories could be justly collapsed under the general rubric of introversion. However, we resisted the temptation to do so for three reasons: first, because of the specificity of the phrases associated with each category, which suggested firm lines of demarcation; second, because people might avoid attention, not only of introversion, but also out of anxiety or neuroticism; and third, because people might wish to be unobtrusive, not because they were introverted or neurotic, but because they felt undeserving of, or embarrassed by, praise. 
Prototypical Modesty

${ }^{6}$ The degrees of freedom for data derived from "correct" and "error" trials are fewer because, for some individual clusters - and hence for some derivative pairs of clusters - participants provided either only correct or only erroneous responses, meaning that only data of one sort were available.

${ }^{7}$ Or, in the words of the Immortal Bard, "One may smile and smile and be a villain" (Hamlet, Act 1 Scene 5). One might also add that, conversely, frowning need not preclude rectitude. 
Prototypical Modesty

Table 1

Study 1: Categories Exemplifying Modesty, Clustered and Ranked by Prototypicality

\begin{tabular}{|c|c|c|c|}
\hline \multicolumn{2}{|c|}{ Exemplar Information } & \multicolumn{2}{|c|}{ Prototypicality Indices } \\
\hline Cluster & Category & Frequency & Priority \\
\hline \multirow[t]{4}{*}{ Central } & Humble & 36.0 & .47 \\
\hline & Shy & 45.0 & .32 \\
\hline & Solicitous & 30.0 & .20 \\
\hline & Not boastful & 32.5 & .17 \\
\hline \multirow[t]{6}{*}{ Peripheral } & Honest & 13.5 & .52 \\
\hline & Likeable & 13.5 & .48 \\
\hline & Not arrogant & 16.0 & .17 \\
\hline & Attention-avoiding & 16.0 & -.22 \\
\hline & Plain & 12.5 & -.34 \\
\hline & Gracious & 12.5 & -.34 \\
\hline \multirow[t]{13}{*}{ Marginal } & Unassuming & 6.0 & .31 \\
\hline & Polite & 8.5 & .04 \\
\hline & Easygoing & 5.0 & .00 \\
\hline & Confident & 7.0 & -.14 \\
\hline & Good Listener & 5.0 & -.17 \\
\hline & Insecure & 7.5 & -.18 \\
\hline & Unobtrusive & 8.5 & -.19 \\
\hline & Gentle & 5.0 & -.21 \\
\hline & Embarrassed by praise & 6.0 & -.23 \\
\hline & Self-effacing & 5.5 & -.25 \\
\hline & Content & 5.0 & -.29 \\
\hline & Selfless & 8.5 & -.33 \\
\hline & Unpretentious & 5.0 & -.50 \\
\hline
\end{tabular}

Note. Entries in the Frequency column correspond to the total number of listed exemplars falling into each category, averaged across US and UK samples. Entries in the Priority column reflect the extent to which an exemplar tends to appear earlier or later in lists relative to the median value, and vary from +1 to -1 . Categories were sorted into clusters on the basis of ostensible breaks between successive frequency scores, and then ordered within each cluster on the basis of the ranking of priority scores. 
Prototypical Modesty

Table 2

Study 1: Mean Ratings of Categories Exemplifying Modesty along the Dimensions of (A) Positive versus Negative and (B) Hidden versus Observable

\begin{tabular}{|c|c|c|c|}
\hline \multicolumn{2}{|c|}{ Exemplar Information } & \multicolumn{2}{|c|}{ Mean Ratings } \\
\hline Cluster & Category & Positive vs. Negative & Hidden vs. Observable \\
\hline \multirow[t]{4}{*}{ Central } & Humble & 4.76 & $3.82 *$ \\
\hline & Shy & $3.45^{*}$ & 4.34 \\
\hline & Solicitous & 5.27 & 4.19 \\
\hline & Not boastful & 4.71 & 4.19 \\
\hline \multirow[t]{6}{*}{ Peripheral } & Honest & 5.52 & $3.52 *$ \\
\hline & Likeable & 5.59 & 5.09 \\
\hline & Not arrogant & 5.05 & 4.26 \\
\hline & Attention-avoiding & 3.89 & $3.78 *$ \\
\hline & Plain & 4.19 & 4.27 \\
\hline & Gracious & 4.18 & $3.55^{*}$ \\
\hline \multirow[t]{13}{*}{ Marginal } & Unassuming & $3.65 *$ & $3.68 *$ \\
\hline & Polite & 5.64 & 5.15 \\
\hline & Easygoing & 4.58 & 4.42 \\
\hline & Confident & 5.36 & 4.64 \\
\hline & Good Listener & 5.70 & 4.70 \\
\hline & Insecure & 2.76 & 4.11 \\
\hline & Unobtrusive & 2.67 & 4.09 \\
\hline & Gentle & $\dagger$ & $\dagger$ \\
\hline & Embarrassed by praise & $3.48 *$ & 4.27 \\
\hline & Self-effacing & $3.52 *$ & $3.61 *$ \\
\hline & Content & 5.58 & 4.64 \\
\hline & Selfless & 4.68 & $3.89 *$ \\
\hline & Unpretentious & 5.18 & 4.24 \\
\hline
\end{tabular}

Note. Ratings range from 1 (Negative or Hidden) to 6 (Positive or Observable).

* Does not significantly differ from the scale midpoint at $p<.01$.

† Data missing due to a computer error. 
Figure Captions

Figure 1. Study 2: Rated modesty of hypothetical persons described using exemplars determined earlier to be more or less prototypical of modesty, that is, central, peripheral, marginal, or remote (i.e., non-prototypical).

Figure 2. Study 3: Average number of times participants selected a person from a hypothetical pair as being more modest when that person had been described in terms of an exemplar determined earlier to be more prototypical of modesty. The gap between the prototypicality of the two exemplars varied such that it was either distant (central vs. remote), nearby (central vs. marginal; peripheral vs. remote), or adjacent (central vs. peripheral; peripheral vs. marginal; marginal vs. remote).

Figure 3. Study 3: Average speed with which participants selected a person from a hypothetical pair as being more modest, regardless of whether that person had been described in terms of an exemplar determined earlier to be more or less prototypical of modesty (i.e., averaged across "correct" and "incorrect" responses). The gap between the prototypicality of the two exemplars varied such that it was either distant (central vs. remote), nearby (central vs. marginal; peripheral vs. remote), or adjacent (central vs. peripheral; peripheral vs. marginal; marginal vs. remote). 
Figure 1

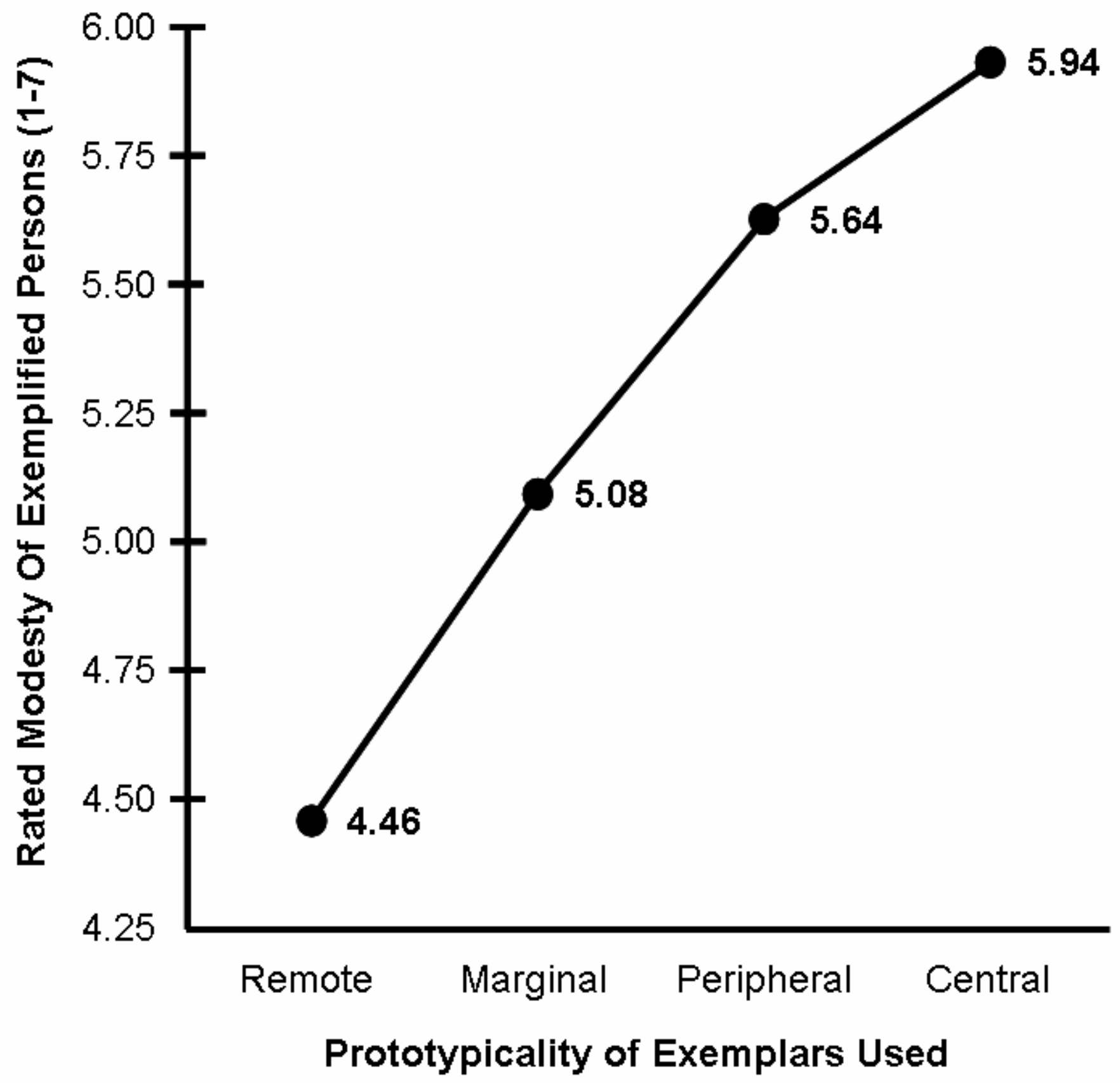


Figure 2

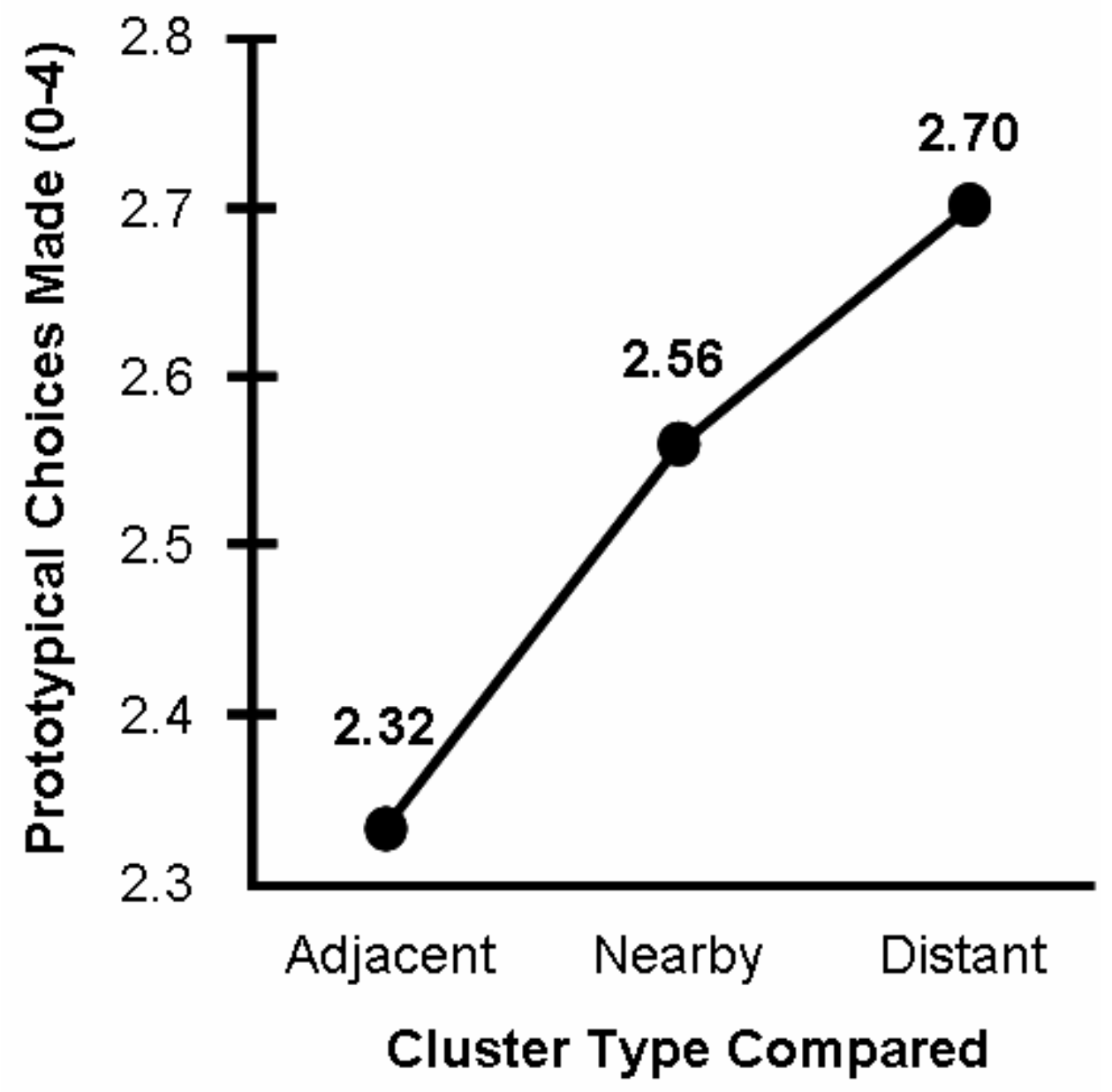




\section{Prototypical Modesty}

Figure 3

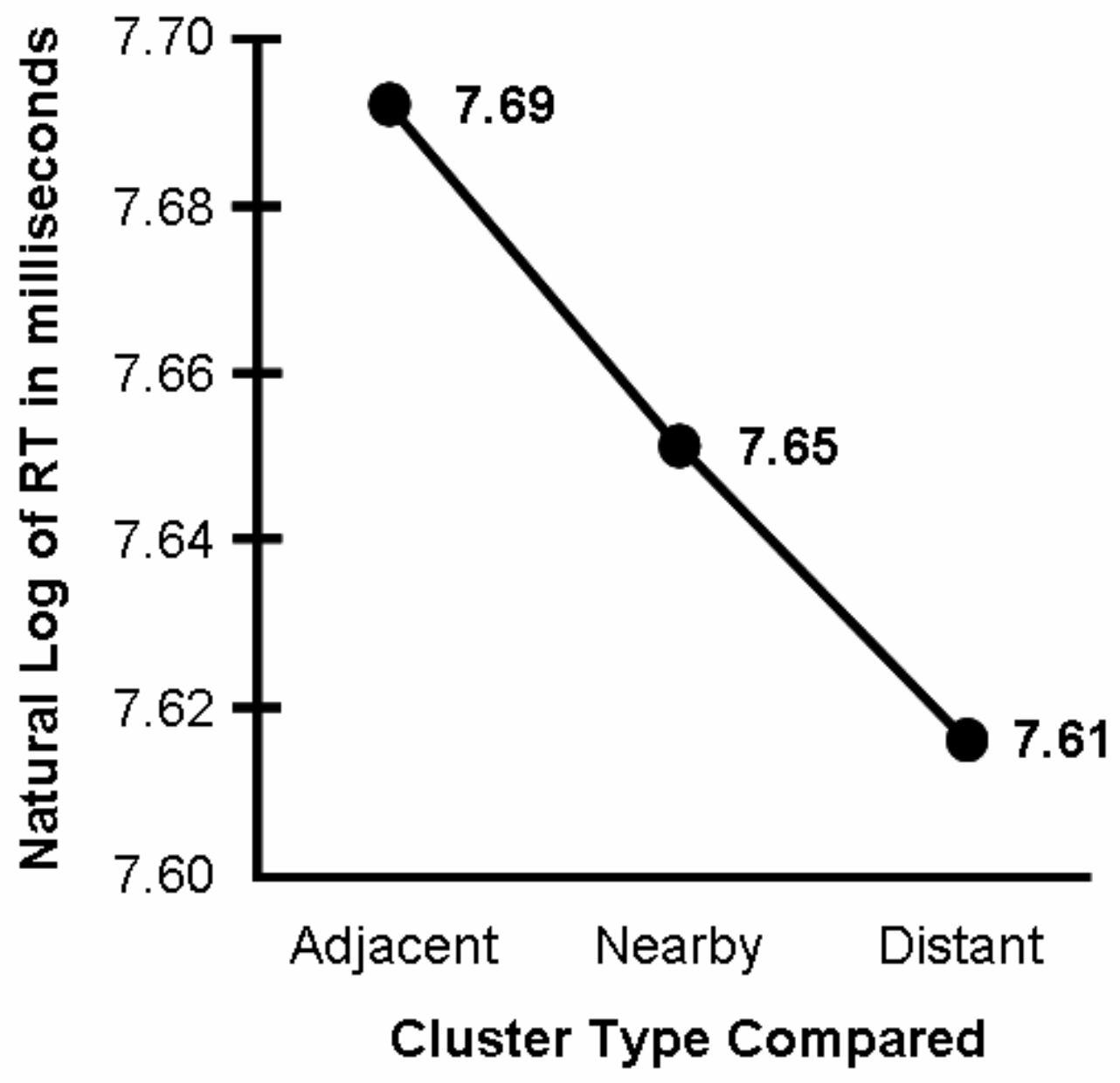

